\title{
On Some New Domination Parameters of Corona Product Graph of a Wheel with a Star
}

\author{
Ch. Hemalatha \\ Trained Graduate Teacher in Mathematics \\ A.P Balayogi Gurukulam \\ Bogole-524152, Andhara Pradesh, India
}

\author{
B. Maheswari \\ Professor (Retd), Department of Applied \\ Mathematics \\ Sri Padmavati Mahila Visvavidyalayam \\ Tirupati-517502, Andhra Pradesh, India
}

\begin{abstract}
The concept of dominating functions are introduced by Hedetniemi [4] and this concept has been studied extensively in recent years.Unidominating function and unidomination number are new concepts introduced by Anantha Lakshmi [1].She has studied these concepts for some standard graphs.

In Discrete Mathematics, Product of graphs occurs naturally as tools in combinatorial constructions. They giverise to important classes of graphs and deep structural problems. Frucht and Harary [3] introduced a new product on two graphs $\mathrm{G}_{1}$ and $\mathrm{G}_{2}$,called corona product denoted by
\end{abstract}

$G_{1} \odot G_{2}$

In this paper the concept of total unidominating function and minimaltotalunidominating function for corona product graphW $_{1, \mathrm{n}} \odot \mathrm{K}_{1, \mathrm{~m}}$ is discussed anddetermined the total unidomination number andupper totalunidominationnumber for this graph. Also the number of total unidominating functions of minimum weight is found.

\section{Keywords}

Total unidominating function, totalunidomination number, minimaltotalunidominating function, upper totalunidomination number

\section{INTRODUCTION}

Domination in graphs is an emerging area of research in graph theory and at present it has been studied extensively. An introduction and an extensive overview on domination in graphs and related topics is surveyed and detailed in the two books by Haynes et al. [5, 6]. The concept of Dominating function in dominating theory arouses much interest of research which has emerged rapidly in the last three decades.

We consider corona product graphs, a new concept introduced by Frucht and Harry [3].The corona of two graphs $\mathrm{G}$ and $\mathrm{H}$ is a graph obtained by taking one copy of $G$ and $|V(G)|$ copies of $\mathrm{H}$ and then joining the $\mathrm{i}^{\text {th }}$ - vertex of $\mathrm{G}$ with all the vertices of the $\mathrm{i}^{\text {th }}$ - copy of $\mathrm{H}$. It is denoted by $\mathrm{G} \odot \mathrm{H}$.

The concept of total dominating function was introduced by Cockayne et al. [2].The total unidominatingfunction and upper total unidomination number are new concepts introduced by Anantha Lakshmi [1] and she studied these concepts for some standard graphs.

\section{CORONA PRODUCT OF $\mathbf{W}_{1, n}$ AND $\mathrm{K}_{1, \mathrm{~m}}$}

The corona product of a wheel graph $\mathrm{W}_{1, \mathrm{n}}$ with a star graph $\mathrm{K}_{1, \mathrm{~m}}$ is a graph obtained by taking one copy of a $(n+1)-$ vertex graph $W_{1, n}$ and $(n+1)$ - copies of $K_{1, m}$ and then joining the $i^{\text {th }}$ - vertex of $W_{1, n}$ to every vertex of $i^{\text {th }}$ - copy of $\mathrm{K}_{1, \mathrm{~m}}$. This is denoted by $\mathrm{W}_{1, \mathrm{n}} \odot \mathrm{K}_{1, \mathrm{~m}}$.

The verticesin $\mathrm{W}_{1, \mathrm{n}}$ are denotedby $\mathrm{v}_{0}, \mathrm{v}_{1}, \ldots \ldots \ldots . . . \mathrm{v}_{\mathrm{n}}$, wherev $\mathrm{v}_{0}$ is the centre vertex of $\mathrm{W}_{1, \mathrm{n}}$. The vertices in the $\mathrm{i}^{\text {th }}$ copy ofstar graph $\mathrm{K}_{1, \mathrm{~m}}$ are denoted by $\mathrm{u}_{\mathrm{i} 0}, \mathrm{u}_{\mathrm{i} 1}, \mathrm{u}_{\mathrm{i} 2}, \ldots \ldots . \mathrm{u}_{\mathrm{im}}$.

We now define the total unidominating function and total unidomination number.

\section{TOTAL UNIDOMINATING FUNCTION OF $\mathbf{W}_{1, \mathrm{n}} \odot \mathrm{K}_{1, \mathrm{~m}}$}

In this section we find the total unidomination number of corona product graph $\mathrm{W}_{1, \mathrm{n}} \odot \mathrm{K}_{1, \mathrm{~m}}$. The total unidominating function and total unidomination number are defined as follows.

Definition2.1: Let $\mathrm{G}(\mathrm{V}, \mathrm{E})$ be a connected graph. A function $\mathrm{h}: \mathrm{V} \rightarrow\{0,1\}$ is said to be a total unidominating function, if

$$
\begin{gathered}
\sum_{u \in N(v)} h(u) \geq 1 \quad \forall v \in \operatorname{Vand} h(v)=1, \\
\sum_{u \in N(v)} h(u)=1 \quad \forall v \in \operatorname{Vand} h(v)=0 .
\end{gathered}
$$

WhereN(v) is the open neighbourhood of the vertexv.

Definition2.2: The total unidomination number of a connected graph $G(V, E)$ is defined $\operatorname{asmin}\{\mathrm{h}(\mathrm{V}) / \mathrm{h}$ is a total unidominating function $\}$.

It is denoted by $\gamma_{\mathrm{tu}}(\mathrm{G})$.

$$
\text { Here } h(V)=\sum_{u \in V} h(u) \text { is called as the weight of }
$$

the total unidominating function $\mathrm{f}$.

That is the total unidomination number of a graph $G(V, E)$ is the minimum of the weights of the total unidominating functions of $\mathrm{G}$.

In what follows we determine the total unidominating function and total unidomination number of $\mathrm{W}_{1, \mathrm{n}} \odot \mathrm{K}_{1, \mathrm{~m}}$.

Theorem2.1: The total unidomination number of the corona product graph $\mathrm{W}_{1, \mathrm{n}} \odot \mathrm{K}_{1, \mathrm{~m}}$ is $\mathrm{n}+1$.

Proof:Consider the graphW ${ }_{1, \mathrm{n}} \odot \mathrm{K}_{1, \mathrm{~m}}$.

To find the total unidomination number of $\mathrm{W}_{1, \mathrm{n}} \odot \mathrm{K}_{1, \mathrm{~m}}$, the procedure is as follows. 
Define a function $\mathrm{h}: \mathrm{V} \rightarrow\{0,1\}$ by

$h\left(v_{i}\right)=1, v_{i} \in W_{1, n}$ for $i=0,1,2, \ldots . n$,

$h\left(u_{i}\right)=0, u_{i} \in K_{1, m}$ for $i=0,1,2, \ldots, n$,

and $h\left(u_{i j}\right)=0, u_{i j} \in K_{1, m}$ for $i=0,1,2, \ldots ., n ; j=1,2, \ldots, m$.

Now we verify that $\mathrm{h}$ is a total unidominating function.

If $\mathrm{v}_{0} \in \mathrm{W}_{1, \mathrm{n}}$, then

$$
\begin{aligned}
\sum_{u \in N\left(v_{0}\right)} h(u)= & h\left(v_{1}\right)+\cdots+h\left(v_{n}\right)+h\left(u_{0}\right)+h\left(u_{01}\right)+\cdots \\
& +h\left(u_{0 m}\right) \\
= & \underbrace{(1+1+\cdots+1)}_{\text {n-times }}+\underbrace{(0+0+\cdots+0)}_{m+1-\text { times }} \\
= & n .
\end{aligned}
$$

Supposei $\neq 0$.

If $v_{i} \in W_{1, n}$, then

$$
\begin{aligned}
\sum_{u \in N\left(v_{i}\right)} h(u)= & h\left(v_{i-1}\right)+h\left(v_{i+1}\right)+h\left(v_{0}\right)+h\left(u_{i}\right)+h\left(u_{i 1}\right) \\
& +\cdots+h\left(u_{i m}\right) \\
= & 1+1+1+\underbrace{(0+0+\cdots+0)}_{m+1-\text { times }}=3 .
\end{aligned}
$$

If $u_{i} \in K_{1, m}$, then

$$
\begin{gathered}
\sum_{u \in N\left(u_{i}\right)} h(u)=h\left(v_{i}\right)+h\left(u_{i 1}\right)+h\left(u_{i 2}\right)+\cdots+h\left(u_{i m}\right) \\
=1+0+0+\cdots+0+0=1 .
\end{gathered}
$$

If $u_{i j} \in K_{1, m}$ for $i=0,1,2, \ldots \ldots \ldots, n ; j=1,2, \ldots \ldots \ldots, m$, then

$$
\sum_{u \in N\left(u_{i j}\right)} h(u)=h\left(v_{i}\right)+h\left(u_{i}\right)=1+0=1 .
$$

Thush becomes a total unidominating function.

$$
\begin{aligned}
& \text { Now } h(V) \\
& =\sum_{u \in V} h(u)=\sum_{u \in W_{1, n}} h(u)+\sum_{u \in K_{1, m}} h(u) \\
& =\underbrace{(1+1+\cdots+1)}_{\mathrm{n}+1-\text { times }}
\end{aligned}
$$

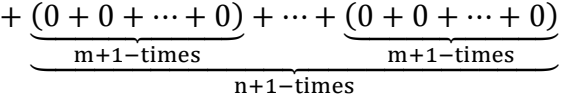

$$
\begin{aligned}
& =\mathrm{n}+1 \text {. }
\end{aligned}
$$

Thereforeh $(V)=n+1$.

Now for all other possibilities of assigning values 0 and 1 to the vertices of $W_{1, n}$ and vertex $u_{i}$ and vertices $u_{i j}$ in each copy of $K_{1, \mathrm{~m}}$, we can see that the resulting functions are not total unidominating functions.

Therefore the function defined as above is the only total unidominating function.

As $h(V)=n+1$ for this function it follows that

$\Upsilon_{\mathrm{tu}}\left(\mathrm{W}_{1, \mathrm{n}} \odot \mathrm{K}_{1, \mathrm{~m}}\right)=\mathrm{n}+1$

Theorem2.2: The number of total unidominating functions of $\mathrm{W}_{1, \mathrm{n}} \odot \mathrm{K}_{1, \mathrm{~m}}$ with minimum weight $\mathrm{n}+1$ is 1 .

Proof: Follows by Theorem 2.1.

\section{UPPER TOTAL UNIDOMINATION NUMBER OF $W_{1, n} \odot K_{1, m}$}

In this section the concept of upper total unidominationis discussed and this number is obtained for the corona product $\operatorname{graphW}_{1, \mathrm{n}} \odot \mathrm{K}_{1, \mathrm{~m}}$.

For this we need the concepts of minimal total unidominating function and upper total unidomination number and they are defined as follows.

Definition3.1: Let $\mathrm{G}(\mathrm{V}, \mathrm{E})$ be a connected graph.A total unidominating function

$\mathrm{h}: \mathrm{V} \rightarrow\{0,1\}$ is called a minimal total unidominating function if for all $\mathrm{g}<h, g$ is not a total unidominating function.

Definition 3.2: The upper total unidomination number of a connected graph $\mathrm{G}(\mathrm{V}, \mathrm{E})$ is defined as

$\max \{\mathrm{h}(\mathrm{V}) / \mathrm{h}$ is a minimal total unidominating function $\}$.

It is denoted by $\Gamma_{\mathrm{tu}}(\mathrm{G})$.

In what follows we determine the minimal total unidominating function and upper total unidomination number of above corona product graph $\mathrm{W}_{1, \mathrm{n}} \odot \mathrm{K}_{1, \mathrm{~m}}$.

Theorem 3.1:The upper total unidomination number of the corona product graph $\mathrm{W}_{1, \mathrm{n}} \odot \mathrm{K}_{1, \mathrm{~m}}$ is $\mathrm{n}+1$.

Proof:Consider the graph $\mathrm{W}_{1, \mathrm{n}} \odot \mathrm{K}_{1, \mathrm{~m}}$.

To find the upper total unidomination number of $\mathrm{W}_{1, \mathrm{n}} \odot \mathrm{K}_{1, \mathrm{~m}}$, the procedure is as follows.

Case 1:Define a function $\mathrm{h}: \mathrm{V} \rightarrow\{0,1\}$ by

$h\left(v_{i}\right)=1, v_{i} \in W_{1, n}$ for $i=0,1,2, \ldots . n$,

$h\left(u_{i}\right)=0, u_{i} \in K_{1, m}$ for $i=0,1,2, \ldots, n$,

$\operatorname{andh}\left(u_{i j}\right)=0, u_{i j} \in K_{1, m}$ for $i=0,1,2, \ldots, n ; j=1,2, \ldots, m$.

This function is same as to the function $\mathrm{h}$ defined in Theorem 2.1 and it is shown that $\mathrm{h}$ is a total unidominating function.

Now we check for the minimality of $h$.

Define a function $\mathrm{g}: \mathrm{V} \rightarrow\{0,1\}$ by

$$
g\left(v_{i}\right)=\left\{\begin{array}{lr}
0 & \text { for } v_{i}=v_{k} \in W_{1, n} \text { for some } k \\
1 & \text { otherwise, }
\end{array}\right.
$$

$g\left(u_{i}\right)=0, u_{i} \in K_{1, m}$ for $i=0,1,2, \ldots \ldots n$,

and $g\left(u_{i j}\right)=0, u_{i j} \in K_{1, m} \quad$ for $\quad i=0,1,2, \ldots \ldots n ; j=$ $0,1,2, \ldots \ldots \mathrm{m}$.

Then by the definition of $\mathrm{g}$ it is obvious that $\mathrm{g}<f$.

Supposei $=\mathrm{k}$.

If $\mathrm{v}_{\mathrm{k}} \in \mathrm{W}_{1, \mathrm{n}}$, then 


$$
\begin{gathered}
\sum_{\mathrm{u} \in \mathrm{N}\left(\mathrm{v}_{\mathrm{k}}\right)} \mathrm{g}(\mathrm{u})=\mathrm{g}\left(\mathrm{v}_{\mathrm{k}-1}\right)+\mathrm{g}\left(\mathrm{v}_{\mathrm{k}+1}\right)+\mathrm{g}\left(\mathrm{u}_{\mathrm{k}}\right)+\mathrm{g}\left(\mathrm{u}_{\mathrm{k} 1}\right) \\
+\ldots \ldots+\mathrm{g}\left(\mathrm{u}_{\mathrm{km}}\right) \\
+\ldots+1+1+0+\cdots+0=2 .
\end{gathered}
$$

That is the condition for total unidominating function fails in the neighbourhood of the vertex $v_{k} \in W_{1, n}$ where $g\left(v_{k}\right)=0$.

Thus $\mathrm{g}$ is not a total unidominating function.

Since $g$ is defined arbitrarily, it follows that there exists no $\mathrm{g}<h$ such that $\mathrm{g}$ is a total unidominaating function.

Hence $\mathrm{h}$ is a minimal total unidominating function.

Further $\mathrm{h}$ is the only one minimal total unidominating function because any other possible assignment of values 0 and 1 to the vertices of $C_{n}$ and $W_{1, m}$ does not make $h$ no more a total unidominating function.

$$
\begin{aligned}
\text { Now } h(V) & =\sum_{\mathrm{u} \in \mathrm{V}} \mathrm{h}(\mathrm{u})=\sum_{\mathrm{u} \in \mathrm{W}_{1, \mathrm{n}}} \mathrm{h}(\mathrm{u})+\sum_{\mathrm{u} \in \mathrm{K}_{1, \mathrm{~m}}} \mathrm{~h}(\mathrm{u}) \\
& =\underbrace{(1+1+\cdots+1)}_{\mathrm{n}+\text {-times }} \\
& +\underbrace{(0+0+\cdots+0)}_{\mathrm{n}+1-\text { times }}+\cdots+\underbrace{(0+1-\text { times }}_{\mathrm{m}+\text {-times }}
\end{aligned}
$$$$
=\mathrm{n}+1 .
$$

Thus $\mathrm{h}(\mathrm{V})=\mathrm{n}+1$.

Now $\max \{\mathrm{h}(\mathrm{V}) / \mathrm{h}$ is a minimal total unidominating function $\}=n+1$, because $h$ is the only one minimal total unidominating function.

Therefore $\Gamma_{\mathrm{tu}}\left(\mathrm{W}_{1, \mathrm{n}} \odot \mathrm{K}_{1, \mathrm{~m}}\right)=\mathrm{n}+1$.

Theorem 3.2: The number of minimal total unidominating functions of $\mathrm{W}_{1, \mathrm{n}} \odot \mathrm{K}_{1, \mathrm{~m}}$ with maximum weight $\mathrm{n}+1$ is 1 .

Proof: Follows by Theorem 3.1.

\section{ILLUSTRATION}

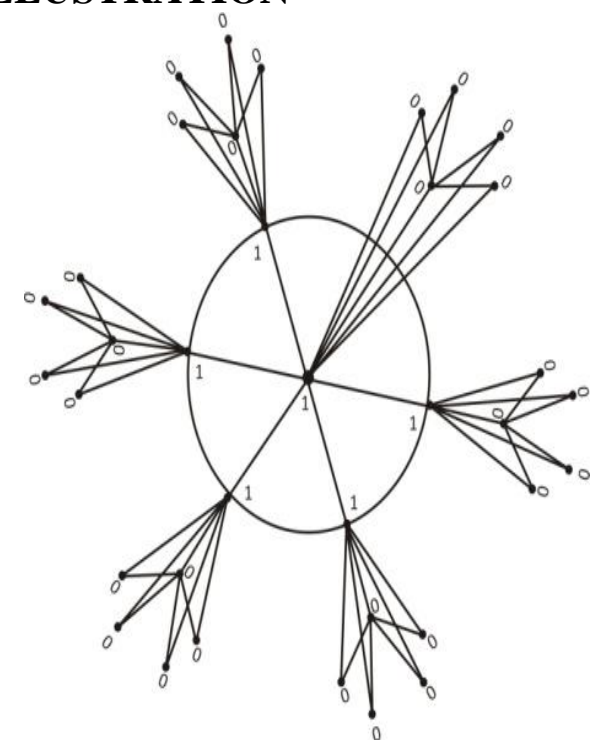

Fig 1. $\mathrm{W}_{1,5} \Theta \mathrm{K}_{1,4}$

The total unidomination number and upper total unidomination number of the corona product graph $\mathrm{W}_{1,5} \odot \mathrm{K}_{1,4}$ is 6 .

\section{CONCLUSION}

The study of corona product of standard graphs is interesting and it gives scope for further investigations on these graphs. Finding unidomination number and upper unidomination number of corona product graph of a wheel with a star throws light on further study of corona product graphs of some other standard graphs such as cycle with a path, cycle with a wheel and etc.

\section{REFERENCES}

[1] Anantha Lakshmi, V. A Study on Unidominating and Total Unidominating functions of Some Standard Graphs, Ph.D. thesis, Sri Padmavati Mahila Visvavidyalayam, Tirupati, Andhra Pradesh, India, (2015).

[2] Cockayne, E.J Mynhardt, C.M Yu, B Total dominating functions in trees: Minimality and Convexity, Journal of Graph Theory, 19(1995), 83-95.

[3] Frucht, R. Harary, F, On the corona of Two Graphs. Aequationes Mathematicae, 1970, Volume4, Issue 3, pp. 322-325.

[4] Hedetniemi S .M, Hedetniemi, S.T. and Wimer, T. V. Linear time resource allocation algorithms for trees. Technical report URI - 014, Department of Mathematics, Clemson University, 1987.

[5] T.W. Haynes, T. Hedetniemi, and P.J. Slater, Fundamentals of Domination in Graphs, Marcel Dekker, New York, 1998.

[6] T.W. Haynes, S.T. Hedetniemi, and P.J. Slater, Domination in Graphs: Advanced Topics, Marcel Dekker, New York, 1998. 